\title{
Molecular analysis of the APC and MUTYH genes in Galician and Catalonian FAP families: a different spectrum of mutations? Nuria Gómez-Fernández ${ }^{1}$, Sergi Castellví-Bel ${ }^{2}$, Ceres Fernández-Rozadilla1, Francesc Balaguer ${ }^{2}$, Jenifer Muñoz ${ }^{1}$, Irene Madrigal ${ }^{3}$, Montserrat Milà ${ }^{3}$, Begoña Graña ${ }^{4}$, Ana Vega ${ }^{1}$, Antoni Castells ${ }^{2}$, Ángel Carracedo ${ }^{1}$ and Clara Ruiz-Ponte*1
}

\author{
Address: ${ }^{1}$ Fundación Pública Galega de Medicina Xenómica (FPGMX)-SERGAS, Grupo de Medicina Xenómica (GMX)-USC, CIBERER, Santiago \\ de Compostela, Galicia, Spain, ${ }^{2}$ Departmento de Gastroenterología, Institut de Malalties Digestives i Metabòliques, Hospital Clínic, CIBEREHD, \\ IDIBAPS, Barcelona, Catalonia, Spain, ${ }^{3}$ CIBER-ER, Departamento de Bioquímica y Genética Molecular, Hospital Clínic, IDIBAPS, Barcelona, \\ Catalonia, Spain and ${ }^{4}$ Servicio de Oncoloxía Médica, Hospital Clínico-CHUS. Santiago de Compostela, Galicia, Spain \\ Email: Nuria Gómez-Fernández - nuria.gomez@usc.es; Sergi Castellví-Bel - sbel@clinic.ub.es; Ceres Fernández- \\ Rozadilla - ceres.fernandez@usc.es; Francesc Balaguer - fprunes@clinic.ub.es; Jenifer Muñoz - jenifer.munoz@ciberehd.org; \\ Irene Madrigal - imadriba@gmail.com; Montserrat Milà - mmila@clinic.ub.es; Begoña Graña - begona.grana.suarez@sergas.es; \\ Ana Vega - ana.vega@usc.es; Antoni Castells - castells@clinic.ub.es; Ángel Carracedo - angel.carracedo@usc.es; Clara Ruiz- \\ Ponte* - clara.ruiz.ponte@usc.es \\ * Corresponding author
}

Published: 16 June 2009

BMC Medical Genetics 2009, 10:57 doi:10.1 186/147|-2350-10-57
Received: II December 2008

Accepted: 16 June 2009

This article is available from: http://www.biomedcentral.com/I47I-2350/I0/57

(C) 2009 Gómez-Fernández et al; licensee BioMed Central Ltd.

This is an Open Access article distributed under the terms of the Creative Commons Attribution License (http://creativecommons.org/licenses/by/2.0), which permits unrestricted use, distribution, and reproduction in any medium, provided the original work is properly cited.

\begin{abstract}
Background: Familial adenomatous polyposis (FAP) is an autosomal dominant-inherited colorectal cancer syndrome, caused by germline mutations in the APC gene. Recently, biallelic mutations in MUTYH have also been identified in patients with multiple colorectal adenomas and in APC-negative patients with FAP. The aim of this work is therefore to determine the frequency of $A P C$ and MUTYH mutations among FAP families from two Spanish populations.

Methods: Eighty-two unrelated patients with classical or attenuated FAP were screened for APC germline mutations. MUTYH analysis was then conducted in those APC-negative families and in 9 additional patients from a previous study. Direct sequencing, SSCP analysis and TaqMan genotyping were used to identify point and frameshift mutations, meanwhile large rearrangements in the APC gene were screened by multiplex ligation-dependent probe amplification (MLPA).

Results: APC germline mutations were found in $39 \%$ of the patients and, despite the great number of genetic variants described so far in this gene, seven new mutations were identified. The two hotspots at codons I06I and I 309 of the APC gene accounted for $9,4 \%$ of the APC-positive families, although they were underrepresented in Galician samples. The deletion at codon $106 \mathrm{I}$ was not found in 19 APC-positive Galician patients but represented $23 \%$ of the Catalonian positive families $(p=0,058)$. The same trend was observed at codon 1309, even though statistical analysis showed no significance between populations. Twenty-four percent of the APC-negative patients carried biallelic MUTYH germline mutations, and showed an attenuated polyposis phenotype generally without extracolonic manifestations. New genetic variants were found, as well as the two hotspots already reported (p.Tyr 165Cys and p.Gly382Asp).
\end{abstract}




\begin{abstract}
Conclusion: The results we present indicate that in Galician patients the frequency of the hotspot at codon 1061 in APC differs significantly from the Catalonian and also other Caucasian populations. Similar results had already been obtained in a previous study and could be due to the genetic isolation of the Galician population. MUTYH analysis is also recommended for all APC-negative families, even if a recessive inheritance is not confirmed.
\end{abstract}

\section{Background}

Familial adenomatous polyposis (FAP; OMIM\#175100) is a rare autosomal dominant colorectal cancer predisposition syndrome, characterised by the presence of hundreds to thousands of adenomatous polyps in the colon and rectum from an early age. In the absence of prophylactic surgery, colorectal cancer (CRC) is the inevitable consequence of FAP. Extracolonic manifestations such as osteomas, congenital hypertrophy of the retinal pigment epithelium (CHRPE), desmoid tumors, sebaceous cysts, hepatoblastoma, upper gastrointestinal tumors or thyroid carcinoma are also associated with FAP [1]. Attenuated FAP (AFAP) is a clinical variant characterised by the presence of fewer than 100 colonic polyps, and often has a later age of onset of polyposis and CRC [2].

The genetic basis of most cases of FAP is a germline mutation of the adenomatous polyposis coli (APC) gene (5q21), which encodes a tumor suppressor protein involved in regulation of cell proliferation and chromosome segregation [3]. About $90 \%$ of the germline mutations in FAP result in truncation of the APC protein and are mainly located within exon 15 [4]. In AFAP, germline mutations have been generally detected either in exon 9 or the 5' and 3' ends of the gene [5].

It is known that APC germline mutations are not present in approximately $10-30 \%$ of FAP patients and in up to $90 \%$ of AFAP patients [6]. Recently, patients with multiple colorectal adenomas and also patients with FAP but without detectable germline APC mutations have been found to carry biallelic mutations in the base-excision-repair gene MUTYH (MYH) [7]. This base excision repair (BER) pathway is necessary to repair DNA damage caused by reactive oxygen species. The DNA glycosylase MUTYH removes adenines from mispairs with 8-oxoguanine that occur during the replication of oxidized DNA. Failure to correct these mispairs consequently leads to $\mathrm{G}: \mathrm{C} \rightarrow \mathrm{T}: \mathrm{A}$ tranversion mutations in tumors that resulted in the discovery of MUTYH-associated polyposis (MAP), which shows an autosomal recessive inheritance pattern [8]. Two mutational hotspots have been so far identified in the MUTYH gene: p.Tyr165Cys and p.Gly382Asp, accounting for approximately $78 \%$ of the mutations identified in affected Caucasians [9].
In this study, we examined the mutational spectrum of the APC gene in patients with polyposis from two Spanish populations, and also the contribution of MUTYH germline mutations in those APC-negative patients.

\section{Methods}

\section{Patients and DNA isolation}

The sample studied consisted of 82 unrelated cases with FAP ( $>100$ colorectal adenomas) or AFAP (5-100 colorectal adenomas). All the patients were included in the study based on colonoscopic findings and/or positive family history. Forty-eight samples were submitted for mutation analysis at the Galician Public Foundation of Genomic Medicine (FPGMX) from health centers across Galicia, and 34 were attended in the at-risk clinic for CRC of the Hospital Clinic in Barcelona. Written informed consent was obtained for each patient before mutation analysis, according to the protocols approved by the ethics review boards of the Hospitals and in compliance with the Helsinki declaration.

All patients were screened for APC germline mutations, and when negative, MUTYH was analysed. MUTYH was also studied in 9 APC-negative families included in a previous article [10].

Clinical features for patients with detected mutations, including age of onset, number of adenomas, colorectal cancer diagnosis, extracolonic diseases and family history, if present, are listed in Tables 1 (APC) [5,10-20] and 2 (MUTYH) [7,8,21,22].

Genomic DNA from Galician and Catalonian samples was obtained from peripheral blood using the Wizard DNA extraction kit (Promega, Madison, WI), and the QIAamp DNA Blood Mini Kits (Qiagen, Hilden, Germany) respectively. Protocols were performed according to the manufacturer's instructions.

\section{Analysis of the APC gene \\ Sequence variants}

Exonic and intronic splice-site defining regions were amplified for the APC gene. PCR conditions for exon 15 had already been described [10], whereas for exons 1-14, new primers were designed using the Primer3 software 
Table I: Phenotypic features and germline mutations identified in APC-positive patients.

\begin{tabular}{|c|c|c|c|c|c|c|c|c|}
\hline Patient ID & Onset age & Number of Adenomas & CRC & ED & $\begin{array}{l}\text { Family history } \\
\text { (age at diagnosis) }\end{array}$ & Mutation & Exon & Ref \\
\hline GAL-27 & 42 & $>100$ & No & No & $\begin{array}{l}\text { Father: } \operatorname{CRC}(36) \\
\text { Grandmother: } \operatorname{CRC}(60)\end{array}$ & c.(?_30)_(*220_?)del & Whole allele & {$[\mathrm{II}]$} \\
\hline GAL-16 & 23 & 100 & No & DT OST & NA & c.(?_30)_(*220_?)del & Whole allele & {$[\mathrm{II}]$} \\
\hline GAL-I4 & 20 & $>100$ & No & $?$ & No & c. I-?_8532+?del & 1 to 15 & [12] \\
\hline GAL-07 & 50 & 15 & No & No & Affected mother (?) & $\begin{array}{l}\text { c.147-I50delACAA } \\
\text { (p.Lys49AsnfsX20) }\end{array}$ & 2 & This study \\
\hline GAL-I5 & 33 & $>100$ & No & $?$ & No & c.423-?_531+?del & 4 & {$[5]$} \\
\hline GAL-I I & 41 & $>100$ & Yes & No & Father: CRC (?) & c.646C>T (p.Arg216X) & 6 & {$[13]$} \\
\hline GAL-26 & 15 & $>100$ & No & No & Father: FAP+CRC (47) & c.646 C>T (p.Arg2।6X) & 6 & [13] \\
\hline GAL-09 & 33 & 12 & No & No & No & c. $994 \mathrm{C}>\mathrm{T}$ (p.Arg332X) & 9 & {$[5]$} \\
\hline GAL-10 & 64 & 50 & Yes & No & $\begin{array}{c}\text { Mother: CRC (68) Aunt: } \\
\text { CRC (60) }\end{array}$ & $\begin{array}{c}\text { c. } 1072 C>T \\
(p . G \ln 358 X)\end{array}$ & 9 & {$[14]$} \\
\hline GAL-19 & NA & $20-50$ & No & No & Mother: CRC (46) & $\begin{array}{l}\text { c. } 1402 \text { G>T } \\
\text { (p.Glu468X) }\end{array}$ & 10 & This study \\
\hline GAL-13 & 20 & $>100$ & Yes & No & No & $\begin{array}{l}\text { c.1620_162IdupA } \\
\text { (p.Gln54IThrfsX19) }\end{array}$ & 12 & {$[15]$} \\
\hline GAL-I8 & 33 & $>50$ & No & No & Father: CRC (42) & $\begin{array}{c}\text { c.1682dupA } \\
\text { (p.Thr562Asnfs X19) }\end{array}$ & 13 & {$[10]$} \\
\hline GAL-02 & 30 & 0 & No & PC & No & $\begin{array}{l}\text { c. } 1756 \text { A>T } \\
\text { (p.Lys586X) }\end{array}$ & 14 & {$[16]$} \\
\hline GAL-0I & 23 & $<100$ & No & No & Brother: FAP (20s) & $\begin{array}{l}\text { c. } 2413 \mathrm{C}>\mathrm{T} \\
(\text { p.Arg805X) }\end{array}$ & 15 & {$[17]$} \\
\hline GAL-I7 & 41 & 100 & Yes & OST & $\begin{array}{c}\text { Father CRC (45), Sister } \\
\text { CRC (34) }\end{array}$ & $\begin{array}{c}\text { c.2900delT } \\
\text { (p.Val967AlafsX13) }\end{array}$ & 15 & This study \\
\hline GAL-I 2 & 34 & $<100$ & No & No & $\begin{array}{c}\text { Father: CRC (40s) } \\
\text { Uncle: CRC (40s) } \\
\text { Grandfather: CRC(40s) }\end{array}$ & $\begin{array}{l}\text { c.3467_3470delAAGA } \\
\text { (p.Glul I56GlyfsX8) }\end{array}$ & 15 & {$[18]$} \\
\hline GAL-24 & 52 & $>100$ & No & CHRPE & No & $\begin{array}{l}\text { c.3927_393I delAAAGA } \\
\text { (p.Glu I 309AspfsX4) }\end{array}$ & 15 & {$[18]$} \\
\hline GAL-04 & 60 & $>100$ & Yes & Others & No & $\begin{array}{c}\text { c.4033G }>\mathrm{T} \\
(\text { p.Glu } 345 \mathrm{X})\end{array}$ & 15 & {$[19]$} \\
\hline GAL-25 & 43 & $>100$ & Yes & No & NA & $\begin{array}{l}\text { c.42I 9-4220delAG } \\
\text { p.Ser|407Xfs XI }\end{array}$ & 15 & This study \\
\hline CAT-I2 & 21 & $>100$ & No & No & $\begin{array}{c}\text { Mother: FAP+ CRC (49) } \\
\text { Sister: FAP (3I) }\end{array}$ & c.(?_30)_(*220_?)del & Whole allele & {$[\mathrm{II}]$} \\
\hline
\end{tabular}


Table I: Phenotypic features and germline mutations identified in APC-positive patients. (Continued)

\begin{tabular}{|c|c|c|c|c|c|c|c|c|}
\hline CAT-13 & 20 & $20-50$ & No & No & $\begin{array}{c}\text { Father: FAP (?) Brother: } \\
\text { FAP (?) }\end{array}$ & c.423-?_53I+?del & 4 & {$[5]$} \\
\hline CAT-0I & 46 & 100 & Yes & No & $\begin{array}{l}\text { Brother: CRC+FAP(53) } \\
\text { Brother: CRC+FAP(59) }\end{array}$ & c.994C>T (p.Arg332X) & 9 & [5] \\
\hline CAT-02 & 32 & $>100$ & No & DP & No & $\begin{array}{l}\text { c.2934_2935delAA } \\
\text { (p.GIn978HisfsX6) }\end{array}$ & 15 & This study \\
\hline CAT-03 & 38 & $40-60$ & No & DT & $\begin{array}{c}\text { Father: CRC (46) } \\
\text { Brother: FAP }\end{array}$ & $\begin{array}{l}\text { c.3183_3187delACAAA } \\
\text { (p.Lys I06ILysfsX2) }\end{array}$ & 15 & {$[18]$} \\
\hline CAT-04 & 20 & $>100$ & No & No & $\begin{array}{l}\text { Mother: FAP + CRC (?) } \\
\text { Cousin: CRC (52) }\end{array}$ & $\begin{array}{l}\text { c.3183_3187delACAAA } \\
\text { (p.Lys 106ILysfsX2) }\end{array}$ & 15 & {$[18]$} \\
\hline CAT-05 & 39 & $>100$ & No & DT & Sister: FAP (4I) & $\begin{array}{c}\text { c.3183_3187delACAAA } \\
\text { (p.Lys I06ILysfsX2) }\end{array}$ & 15 & {$[18]$} \\
\hline CAT-06 & 38 & $>100$ & Yes & No & $\begin{array}{l}\text { Brother: FAP Father: } \\
\text { FAP + CRC (?) }\end{array}$ & $\begin{array}{c}\text { c.3329C>A } \\
(\text { p.SerIIIOX) }\end{array}$ & 15 & This study \\
\hline CAT-07 & NA & NA & NA & NA & NA & $\begin{array}{c}\text { c.3329C>A } \\
\text { (p.SerIIIOX) }\end{array}$ & 15 & This study \\
\hline CAT-08 & 27 & $>100$ & No & No & $\begin{array}{c}\text { Brother: FAP (29) } \\
\text { Father: FAP (4I) } \\
\text { Grandmother: FAP(30) }\end{array}$ & $\begin{array}{c}\text { c.353IdelT } \\
\text { (p.Ilell77MetfsX5) }\end{array}$ & 15 & This study \\
\hline CAT-09 & NA & NA & NA & $\mathrm{DP}$ & NA & $\begin{array}{c}\text { c.363I_3632delAT } \\
\text { (p.MetI2IIValfsX5) }\end{array}$ & 15 & {$[20]$} \\
\hline CAT- 10 & 17 & $>100$ & No & FGP & $\begin{array}{c}\text { Father: FAP (39) Uncle: } \\
\text { FAP + CRC (?) }\end{array}$ & $\begin{array}{l}\text { c.3927_393I delAAAGA } \\
\text { (p.GluI 309AspfsX4) }\end{array}$ & 15 & [18] \\
\hline CAT-II & 32 & $>100$ & No & FGP & $\begin{array}{c}\text { Father: FAP (39) } \\
\text { Uncle FAP + CRC(63). } \\
\text { Aunt: FAP+ CRC(55) } \\
\text { Grandmother: } \\
\text { FAP+CRC(39) }\end{array}$ & $\begin{array}{l}\text { c.3927_393I delAAAGA } \\
\text { (p.Glul 309AspfsX4) }\end{array}$ & 15 & {$[18]$} \\
\hline
\end{tabular}

ED: extracolonic disease; DT: desmoid tumor; OST: osteomas; NA: not available; PC: papillary carcinoma; CHRPE: congenital hypertrophy of the retinal pigmented epitelium; Others: Ovarian tumor and suprarenal adenoma; DP: duodenal polyps; FGP: fundic gland polyps.

[23] in order to cover larger intronic regions [see Additional file 1].

Galician samples were analysed by direct DNA sequencing at the FPGMX. For the Catalonian samples, single strand conformational polymorphism (SSCP) analysis was performed at Hospital Clinic as an initial screening, as described [24]. Amplification products larger than 350 bp were previously digested with a suitable restriction enzyme. Any fragment showing a mobility shift was sequenced in order to identify the variant. Sequencing was performed in forward and reverse orientations using the BigDye terminator v.3.1. cycle sequencing kit (Applied Biosystems, Foster City, CA).
Genomic rearrangements

Large genomic rearrangements of the APC gene were evaluated with the APC multiplex ligation-dependent probe amplification (MLPA) kit [25], and performed according to the supplied protocol (SALSA MLPA KIT P043 APC, MRC-Holland, Amsterdam, The Netherlands). The amplicons were analysed in an ABI 3730 sequencer using GeneMapper v3.7 software (Applied Biosystems, Foster City, CA, USA). Peak heights of each fragment were compared to those of a control sample, and deletions or duplications were suspected when peak height differed by over $30 \%$. Control DNA samples with known genomic rearrangements in APC were included in each batch of experiments. Positive results of large rearrangements were repeated in an independent assay and subsequently confirmed by other methods (FISH, cDNA analysis). 
Table 2: Phenotypic characteristics and germlime mutations identified in biallelic MUTYH carriers.

\begin{tabular}{|c|c|c|c|c|c|c|c|c|}
\hline \multirow[t]{2}{*}{ Patient ID } & \multirow[t]{2}{*}{ Onset age } & \multirow[t]{2}{*}{ Number of adenomas } & \multirow[t]{2}{*}{ CRC } & \multirow[t]{2}{*}{ ED } & \multirow{2}{*}{$\begin{array}{l}\text { Family History } \\
\text { (age at diagnosis) }\end{array}$} & \multicolumn{2}{|c|}{ MUTYH } & \multirow[t]{2}{*}{ Ref. } \\
\hline & & & & & & Ist Mutation & $2^{\text {nd }}$ mutation & \\
\hline GAL-08 & 43 & $25-30$ & Yes & No & No & $\begin{array}{c}\text { c. } 494 \mathrm{~A}>\mathrm{G} \\
\text { (p.Tyr 165Cys) }\end{array}$ & $\begin{array}{c}\text { c.494A>G } \\
\text { (p.Tyr 165Cys) }\end{array}$ & [7] \\
\hline GAL-2। & 52 & $<100$ & No & No & No & $\begin{array}{c}\text { c.494A>G } \\
\text { (p.Tyr I65Cys) }\end{array}$ & $\begin{array}{c}\text { c. II } 145 \text { G>A } \\
\text { (p.Gly382Asp) }\end{array}$ & [7] \\
\hline GAL-22 & NA & $40-60$ & No & No & $\begin{array}{l}\text { Two siblings and } \\
\text { mother: CRC (50s) }\end{array}$ & $\begin{array}{c}\text { c. } 494 \mathrm{~A}>\mathrm{G} \\
\text { (p.Tyr 165Cys) }\end{array}$ & $\begin{array}{c}\text { c. I I } 45 \text { G>A } \\
\text { (p.Gly382Asp) }\end{array}$ & [7] \\
\hline GAL-05 & 58 & $<100$ & Yes & No & NA & $\begin{array}{c}\text { c. } 494 A>G \\
\text { (p.Tyr 165Cys) }\end{array}$ & $\begin{array}{l}\text { c. II } 145 \text { G>A } \\
\text { (p.Gly382Asp) }\end{array}$ & {$[7]$} \\
\hline GAL-06 & NA & $40-100$ & No & No & Sister: AFAP (?) & $\begin{array}{c}\text { c. } 494 A>G \\
\text { (p.Tyr 165Cys) }\end{array}$ & $\begin{array}{c}\text { c. I1 } 145 \text { G>A } \\
\text { (p.Gly382Asp) }\end{array}$ & [7] \\
\hline GAL-20 & 45 & $<100$ & No & No & $\begin{array}{l}\text { Two siblings: } \\
\text { AFAP+CRC (?) }\end{array}$ & $\begin{array}{l}\text { c. }|13| \mathrm{C}>\mathrm{T} \\
(\mathrm{p} . \mathrm{Gln} 377 \mathrm{X})\end{array}$ & $\begin{array}{l}\text { c. I I } 45 \text { G>A } \\
\text { (p.Gly382Asp) }\end{array}$ & {$[7,21]$} \\
\hline GAL-03 & 44 & $31-100$ & Yes & No & No & $\begin{array}{c}\text { c.II45 G>A } \\
\text { (p.Gly382Asp) }\end{array}$ & $\begin{array}{c}\text { c. II } 145 \text { G>A } \\
\text { (p.Gly382Asp) }\end{array}$ & [7] \\
\hline GAL-23 & 62 & $>30$ & Yes & No & No & $\begin{array}{l}\text { c.II86_II 87insGG } \\
\text { p.Glu396GlyfsX43 }\end{array}$ & $\begin{array}{l}\text { c.II86_II 87insGG } \\
\text { p.Glu396GlyfsX43 }\end{array}$ & [22] \\
\hline CAT-I5 & 44 & 5 & Yes & No & $\begin{array}{c}\text { Mother: BC(66) } \\
\text { Brother:2 CRC (46) }\end{array}$ & $\begin{array}{c}\text { c. } 494 \mathrm{~A}>\mathrm{G} \\
\text { (p.Tyr 165Cys) }\end{array}$ & $\begin{array}{c}\text { c.II03delC } \\
\text { (p.Ala369AlafsX26) }\end{array}$ & {$[7,8]$} \\
\hline CAT-I4 & 38 & $15-30$ & No & No & Father: CRC (?) & $\begin{array}{c}\text { c.494A>G } \\
\text { (p.Tyr 165Cys) }\end{array}$ & $\begin{array}{c}\text { c. II } 45 \text { G>A } \\
\text { (p.Gly382Asp) }\end{array}$ & [7] \\
\hline CAT-I7 & 60 & $>20$ & Yes & No & NA & $\begin{array}{c}\text { c.II45G>A } \\
\text { (p.Gly382Asp) }\end{array}$ & $\begin{array}{c}\text { c.II45G>A } \\
\text { (p.Gly382Asp) }\end{array}$ & [7] \\
\hline CAT-16 & 45 & $40-50$ & No & No & Father: CRC (40) & $\begin{array}{c}\text { c. II 45G>A } \\
\text { (p.Gly382Asp) }\end{array}$ & $\begin{array}{c}\text { c.II45G>A } \\
\text { (p.Gly382Asp) }\end{array}$ & [7] \\
\hline CAT-I8 & 45 & 70 & Yes & No & No & $\begin{array}{l}\text { c.II86_II87insGG } \\
\text { (p.Glu396GlyfsX43) }\end{array}$ & $\begin{array}{l}\text { c.II86_I I87insGG } \\
\text { (p.Glu396GlyfsX43) }\end{array}$ & [22] \\
\hline CAT-19 & 69 & 0 & Yes & BC (59) & Cousin: CRC (40) & $\begin{array}{l}\text { c.II86_II 187insGG } \\
\text { p.Glu396GlyfsX43 }\end{array}$ & $\begin{array}{l}\text { c.II86_I I 87insGG } \\
\text { p.Glu396GlyfsX43 }\end{array}$ & {$[22]$} \\
\hline
\end{tabular}

ED: Extracolonic disease; BC: Breast cancer; NA: not available.

To allow comparison of our results, we used the MUTYH sequence used by previous authors (GenBank accession number: $\underline{\mathrm{U} 63329}$ ) instead of the actual reference sequence (GenBank accession number: NM 012222), which has II additional codons in exon 3. 


\section{APC FISH}

Fluorescent in situ hybridization (FISH) analysis was performed with RP11-3B10 and RP11-619D06 clones mapping in 5q21-q22. BAC clones were purchased from the BAC/PAC Resources of the Children's Hospital Oakland Research Institute (CHORI, Oakland, CA). Equal amounts of BAC DNA (200 ng) were labelled with Spectrum Orange (RP11-3B10) and Spectrum Green (RP11619D06) by a standard nick-translation (Vysis, Downers Grove, IL, USA). This dual color probe was used to hybridize preparations of fixed cell nuclei and metaphases. Slides were visualized under an epi?uorescence microscope (Leica DMRXA). Images were captured by using a COHU camera and analysed with the Cytovision Ultra Workstation (Applied Imaging, Sunderland, UK).

\section{RT-PCR}

mRNA was isolated from blood using RNeasy ${ }^{\circledR}$ Mini kit (Qiagen, Hilden, Germany). Synthesis of complementary DNA (cDNA) was performed with SuperScript ${ }^{\mathrm{TM}}$ II Reverse Transcriptase (Invitrogen, Carlsbad, USA). cDNA was then amplified using primers located in the adjacent exons to those regions potentially deleted. A positive cDNA control was included in every PCR. Amplification products were sequenced in an ABI3730 analyser.

\section{Analysis of the MUTYH gene}

For every patient without detectable pathogenic mutations in APC, all MUTYH exons and their adjacent intronic splice sites were amplified using primers designed with the Primer3 software [23] [see Additional file 2].

Galician samples were analysed at the FPGMX center by sequencing each amplification fragment, as described above for the APC gene. Real-time PCR using Taqman probes, and SSCP analysis were performed for Catalonian samples at the Hospital Clinic. TaqMan genotyping included the analysis of the two most common mutations found to date in the MUTYH gene: p.Tyr165Cys and p.Gly382Asp, as well as the two rare mutations c.1103delC and c.1186_1187insGG identified in our previous study [26]. This technique is based on allelic discrimination using allele-specific probes resolved on a 7300 Real Time PCR System (Applied Biosystems, Foster City, CA).

\section{Mutation nomenclature}

All mutations were described following the guidelines proposed by the Human Genome Sequence Variation (HGSV) site and were referred to the cDNA sequences of APC (NM_000038) and MUTYH (U63329). Furthermore, all mutations were confirmed in two independent DNA extractions.

\section{Variants of Unknown Significance (VUS)}

We examined 500 chromosomes from control individuals with no personal or family history of colorectal cancer, in order to estimate the frequency of VUS. Analysis was carried out by direct DNA sequencing (see above).

Polyphen software was used to test the potential role of missense variants. This prediction program is based on observed substitutions of the residues in homologous proteins [27].

\section{Statistical analyses}

Ji-squared statistics with Fisher's correction were used to test for differences in APC and MUTYH mutation frequencies between the Galician and the Catalonian populations. Comparisons were also made for mutation frequencies at codons 1061 and 1309 of the APC gene. All statistics were estimated with the SPSS statistical software package (SPSS Inc., Chicago IL).

\section{Results and Discussion APC mutations}

In this study, germline mutations in $A P C$ were found in $39 \%$ (32 out of 82 ) of the Spanish patients with FAP. Frameshift and nonsense mutations were the most frequently identified, and despite the great number of genetic variants described to date in the APC gene, seven new pathogenic mutations and two new VUS were reported. Clinical features displayed by $A P C$-positive patients are shown on Table 1.

Five new frameshift mutations were identified: c.147_150delACAA

(p.Lys49AsnfsX20),c.2900delT(p.Val967AlafsX13),c.2934 _2935delAA(p.Gln978HisfsX6),c.3531delT(Ile1177Metfs X5) and c.4219_4220delAG (p.Ser1407XfsX1) in patients GAL-07, GAL-17, CAT-02, CAT-08 and GAL-25, respectively. All of these mutations were deletions of few nucleotides, that give rise to premature stop codons $(\mathrm{X})$ which would lead to truncated APC proteins. We also identified two additional nonsense mutations that generate premature stop codons: c.1402 G>T (p.Glu468X) in patient GAL-19, and c.3329C>A (p.Ser1110X) in two unrelated patients (CAT-06 and CAT-07).

The two new VUS: c.3165A>G (p.Ile1055Met) and c.5357G >C (p.Arg1786Thr), were found in GAL-47 and GAL-35. Both patients displayed an attenuated FAP phenotype with an onset at around forty. These variants were not detected in 500 chromosomes from a healthy control population. However, their absence from the control group cannot be taken as prove of a deleterious effect. In silico studies using Polyphen revealed the p.Arg1786Thr as "possibly damaging", while the p.Ile1055Met was reported as "benign". In these families it was not possible 


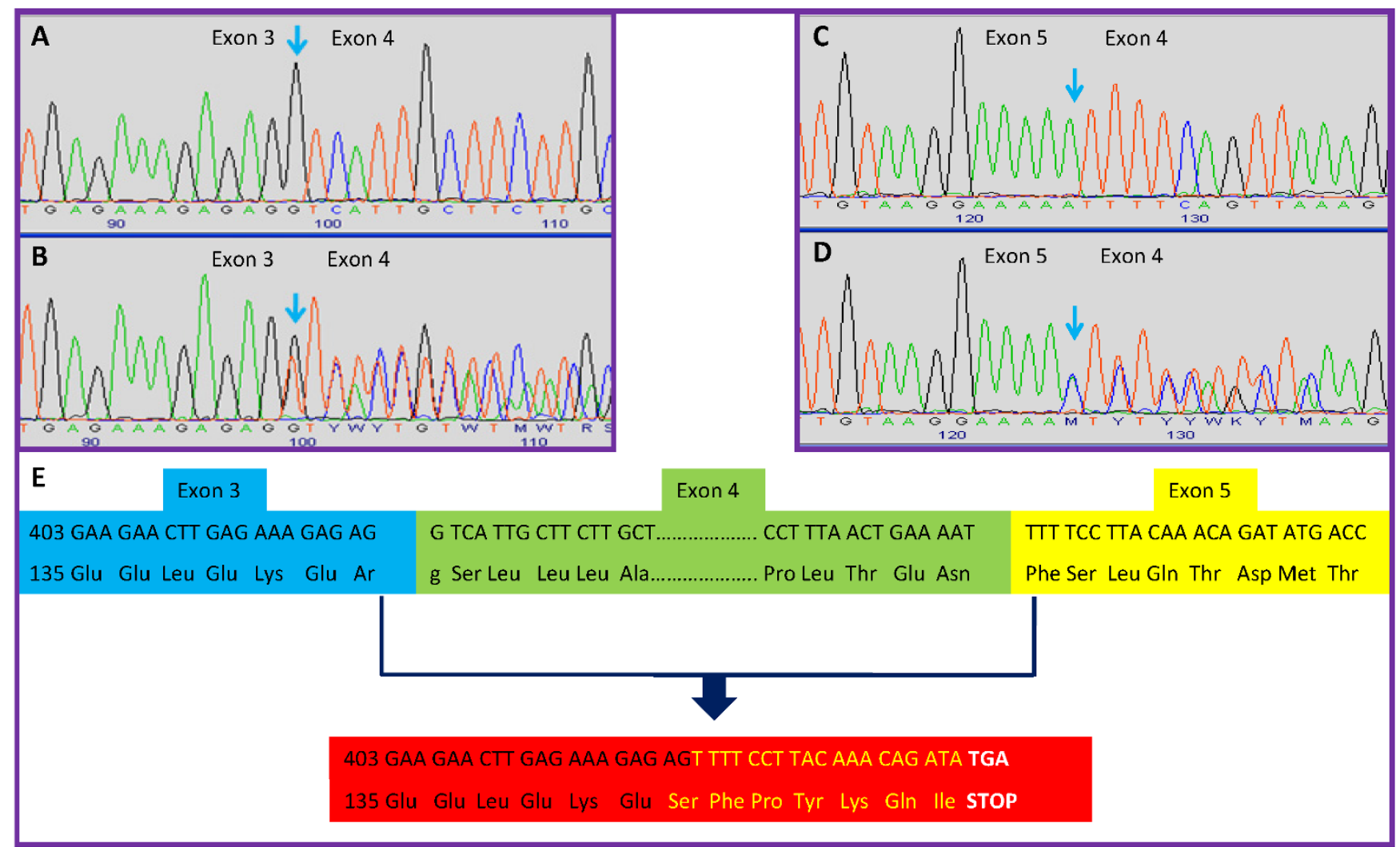

Figure I

CDNA analysis of the APC exon 4 deletion confirming the results obtained by MLPA. A. forward reference sequence; $B$. forward sequence with exon 4 deletion; $C$. reverse reference sequence; $D$. reverse sequence with exon 4 deletion; E. Nucleotidic and aminoacidic sequences showing the effect of the exon 4 deletion, which results in a frameshift that creates a stop codon at residue 442 .

to study the co-segregation with the disease, so further functional studies are necessary to consider them deleterious.

Large genomic deletions were found in 11\% (6/56) of the families that tested APC mutation-negative by conventional techniques. This frequency is consistent with published data that comprise a range between $8-12 \%$ for such rearrangements $[11,12,28]$. Three different deletions were detected in 6 unrelated families: two exon 4 deletions (CAT-13 and GAL-15), an exon 1-15 deletion (GAL-14), and 3 whole-gene deletions (including the promoter) (CAT-12, GAL-27 and GAL-16). All of them were further confirmed by either cDNA studies (Figure 1) or FISH analysis (Figure 2).

Carriers of whole allelic deletions generally displayed a severe polyposis phenotype with an early onset of symptoms, as previously described [11]. A correlation between site of mutation and clinical phenotype was also observed for six of the seven new mutations identified. Mutations occurring at the beginning and middle of exon 15 were generally associated with a more severe phenotype than those located at the 5' and 3' ends of the gene, which is consistent with other studies [29]. Although mutations in exon 10 would then be associated with FAP, p.Glu468X was found in a patient classified as AFAP based on number of polyps (GAL-19) (Table 1).

Phenotypic differences about number of adenomas and extracolonic disease were observed in unrelated probands carrying the p.Lys1061LysfsX2 mutation (CAT-03 and CAT-04) and the whole gene deletions (CAT-12 and GAL16) (Table 1). This phenotypic heterogeneity suggests that either modifier genes, epigenetic mechanisms or environmental factors could modulate the FAP phenotype. There is good evidence from humans, and particularly from mouse models, of the involvement of modifier genes that influence the severity of FAP. It is known that same sex siblings in their early twenties often show phenotypic differences which cannot be easily explained except by the action of modifier genes [30]. Despite those findings, further clinical information and an accurate follow-up of patients is necessary to confirm our results. 
A
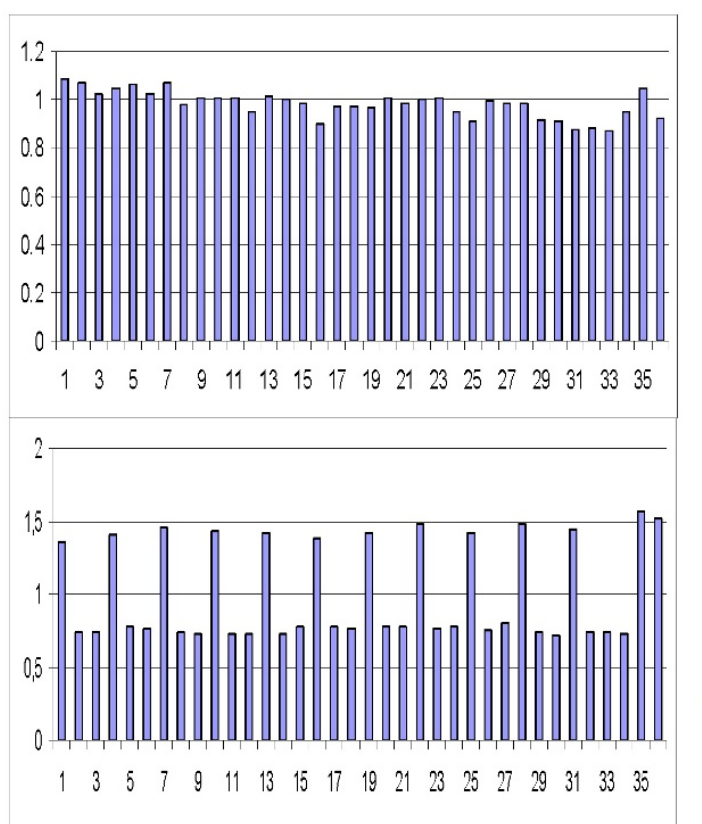

B

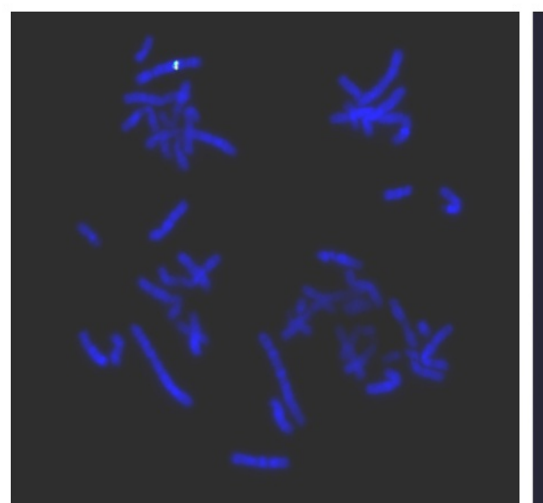

Patient

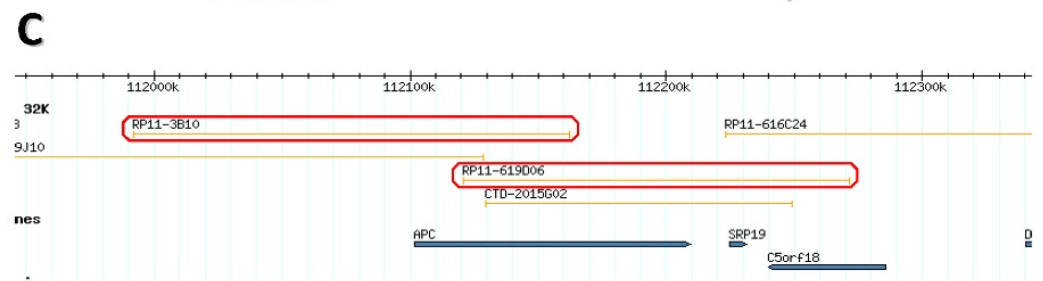

Figure 2

Whole APC gene deletion detected by MLPA and FISH analysis. A. Electropherograms of MLPA products showing a normal control and a deletion of the whole APC gene. B. FISH studies on metaphase spreads with clones RPII-3BI0 (red probe) and RPI I-6I9D06 (green probe) that map within the deletion, on the patient and a healthy sister. C. Physical mapping position, according to the $\mathrm{hgI} 7$ assembly of the UCSC http://genome.ucsc.edu/cgi-bin/hgGateway of clones mapping the $5 \mathrm{q} 2 \mathrm{I}$ 22 region.

The two hotspots at codons 1061 and 1309 of the APC gene accounted in this study for $9.4 \%$ of the $A P C$-positive families. However, they were reported mainly in Catalonian families. Mutation at codon 1061 was detected in 3 (CAT-03, CAT-04 and CAT-05) out of 13 Catalonian positive families (23\%), but was not found in 19 APC-positiveGalician families. A similar trend was observed for the deletion at codon 1309: 15\% (2 out of 13, CAT-10 and CAT-11) for Catalonians vs 5,2\% ( 1 out of 19, GAL-24) for Galician patients. Therefore, we performed statistical analyses in order to test whether the Galician population had a significantly different mutation frequency at these codons. Ji-squared tests yielded significance for the 1061 mutation $(\mathrm{p}=0,058)$ but not for the 1309 variant $(\mathrm{p}=$ $0,356)$.

Although different mutation screening methods were used to study these two populations, the possibility that this fact could have caused the different spectra observed would be very small. Firstly, the mutation frequency in both populations was similar (40\% for Galicia and 38\% for Catalonia, $\mathrm{p}=0.888$ ). Besides, Galician samples were directly sequenced, which was the most sensitive of the techniques used.
Similar results had already been observed in a previous study where 15 unrelated Galician patients were analysed, but in that study it was not possible to establish whether the inability to detect the recurrent mutations at codons 1061 and 1309 actually reflected an underrepresentation of these genetic variations in this population, or was simply due to a sampling bias [10]. Furthermore, when we considered all the data available from the Galician FAP patients altogether (the 19 APC-positive families from this study plus the 6 from our previous one [10]), the frequencies observed were 4\% (1/25 APC-positive) for the 1309 deletion, and still $0 \%$ for the deletion at codon 1061 , which is certainly quite remarkable. Thus, we recalculated the Ji-squared test for the 1309 mutation and a trend towards the underrepresentation of this variant was indeed observed $(\mathrm{p}=0,265)$.

Although there is plenty of evidence that the mutational spectrum of the APC gene varies in different populations, these two hotspots are thoroughly reported worldwide. They represent around $8 \%$ and $20 \%$ of the APC-positive families, and the 5 bp deletion at codon 1309 is reported as the most common germline mutation [31,32]. Interestingly, a frequency range for this deletion in different countries has also been described: a high rate in Japan (14\%), 
a moderate frequency in most European populations (56\%), and no 1309 deletions detected in Australia (0\% out of 27 APC-positive families) [33]. It has also been recently reported that the frequency of the deletion at codon 1061 in 46 Czech and Slovak APC-positive families was lower than the expected (3\%) [34]. The variation in the distribution of these hotspots could presumably be caused by an ascertainment bias, but in isolated populations it could as well be explained by a founder effect. For instance, in the Balearic Islands, where the hotspot at codon 1061 is overrepresented (50\%), the haplotype analysis of the families sharing this deletion was consistent with the presence of a founder effect [35]. The recurrence of these two mutations has been linked to the molecular properties of the DNA region around codons 1061 and 1309, rather than with specific haplotypes. These two are located within a short hypermutable polyA repeat that may associate with an increased probability of DNA polymerase slippage during DNA replication, leading to an overrepresentation of deletions. The high incidence of the 1309 deletion among de novo cases, and the fact that this alteration was found to segregate with different haplotypes associated with the disease supports this hypothesis [33].

It is known that gene diversity in the Galician population is generally lower than in other European populations, as a result of its relative isolation from the rest of the Iberian Peninsula and the high emigration rates during the last two centuries $[36,37]$. These genetic features would have possibly caused the selection of not yet identified allelic variants in DNA repair genes. Hypothetically, those variants would repair more efficiently the DNA polymerase slippage caused by the repetitive sequences around codons 1061 and 1309 during replication. Therefore, lower frequencies for these two APC hotspots should be observed. Such founder effects have already been observed in this population for some genetic diseases, including BRCA1 in familial breast cancer [38].

\section{MUTYH mutations}

Biallelic germline mutations in MUTYH were found in 24\% of the APC-negative patients, i.e., 14/59 (fifty from this study plus 9 from the previous one [10]). This data is consistent with previous results $[39,40]$. Differences between these populations were not significant $(\mathrm{p}=$ $0.517)$.

Table 2 shows that the two most frequent mutations reported to date (p.Tyr165Cys and p.Gly382Asp) were detected in quite a number of cases, the frequency of these alleles being $71 \%$. This observation is comparable to what has been described in the literature $[9,41]$. Among the other mutations found, the c.1186_1187insGG accounted for $21 \%$ of the mutant alleles reported. This mutation was previously reported in Portuguese families with a similar frequency [22].

Biallelic MUTYH carriers displayed an attenuated polyposis phenotype without extracolonic manifestations, with the exception of patient CAT-19 who showed breast cancer at 59 years and CRC at 69 (Table 2). It is noteworthy that the BRCA1 and BRCA2 tumor suppressor proteins participate in the base excision repair of 8-oxo-7,8-dihydroguanine (8-oxoG) lesions [42]. Accordingly, loss of BER function due to biallelic MUTYH mutations may underlie breast cancer risk. In Dutch MAP patients, breast cancer occurred in $18 \%$ of females, significantly more than the expected from national statistics. This observed increased breast cancer risk should be thoroughly investigated [21].

The median age at diagnosis of CRC in MAP families was 51,5 years (ranging from 43 to 69) (Table 2). In contrast, classical FAP patients showed a CRC onset 10 years earlier (median 41, ranging from 20 to 46) (Table 1). As previously reported [8], it appears that disease symptoms in MAP are not as severe as those observed in APC-driven FAP, and that they resemble an attenuated polyposis phenotype. However, patients GAL-08, CAT-15, GAL-03 and CAT-18 presented ambiguous clinical manifestations, with a display of CRC at around their forties, which is more likely a feature of FAP, but a number of polyps and an onset typical of the attenuated phenotype. Hence, we have thought it appropriate to classify them as AFAP. We realise that classification of such patients is difficult, since it is well-known there is a lack of agreement concerning the exact diagnostic criteria that should be used to classify attenuated polyposis [43].

As expected, most of the bilallelic MUTYH carriers were found in families with an autosomal recessive model of inheritance, or in cases with apparent sporadic presentation. However, we identified three patients (CAT-14, GAL22 and CAT-16) with a family history of vertical transmission of CRC; similar results had already been described [44].

Biallelic MUTYH mutations have been consistently linked to higher CRC susceptibility. However, the risk for monoallelic MUTYH carriers remains controversial. Balaguer et al. [26] used a meta-analysis of published case-control studies and concluded that monoallelic MUTYH carriers were not at increased risk for CRC, although an effect of bordeline statistical significance was observed for p.Tyr165Cys. In the present study, monoallelic changes with predicted functional relevance (p.Tyr165Cys, p.Gly382Asp, p.Val232Phe) were found in 3/45 patients, and accounted for $6.7 \%$ of cases. Nevertheless, they were not included as positive within the overall data, even 
though the p.Val232Phe was recently shown to reduce glycosylase activity [45].

Five new VUS were identified: c.-56 G>C, c.39 C>T (p.Ala13Ala), c.269A $>\mathrm{G} \quad$ (p.Tyr90Cys), c.508C $>\mathrm{T}$ (p.Arg170Trp) and c.762 G>A (p.Gln254Gln). We also found p.Arg412Cys, previously described by Aceto et al. [46] and predicted by Polyphen as "possibly damaging". Neither of these variants were found in healthy controls when genotyping 500 chromosomes. It is quite remarkable though, that two of these previously not reported variants (p.Tyr90Cys and p.Arg170Trp), predicted as "probably damaging", were both found in CAT-22. This patient displayed multiple adenomas (50-60) and CRC at 53 years, but had no family history of polyposis. However, further studies are necessary to assess if these two variants are indeed deleterious.

\section{Conclusion}

Our mutation detection rate for the APC gene (39\%) is consistent with previous reports. Using standard methods of mutation analysis, such as sequencing, $11 \%$ of the classical FAP patients would not have been detected, so analysis of large rearrangements of the APC gene is strongly recommended. A genotype-phenotype correlation was found for most of the APC identified mutations, although the inter-family phenotypic variability observed would suggest the existence of genetic and/or environmental modifiers.

Besides, our data regarding the incidence of the 1309 and 1061 deletions in APC could indicate that in Galician patients the frequency of these two hotspot mutations is underrepresented. In our study, codon 1061 proved to be significantly different from the Catalonian and other Caucasian populations. We believe this might be due to the genetic isolation of the Galician population.

Biallelic germline mutations in MUTYH accounted for $24 \%$ of the families analysed, all of which displayed an attenuated polyposis phenotype and a CRC onset 10 years later than FAP. It was observed that a family history of vertical transmission of CRC did not rule out the possibility of biallelic MUTYH mutations.

In short, the overall results resemble those previously published and confirm that large rearrangements represent an important percentage of APC germline mutations. The lower frequency observed for the two hotspots of APC in Galician families has probably lead to a higher heterogeneity of APC mutations in this population. MUTYH analysis is also recommended for all $A P C$-negative families even if a recessive inheritance is not confirmed. From a molecular point of view, these findings altogether have important implications for the design of mutation detection strategies, especially in Galician FAP families.

\section{Competing interests}

The authors declare that they have no competing interests.

\section{Authors' contributions}

NGF carried out the molecular genetic analysis in the Galician samples, mainly the analysis of large rearrangements in $A P C$ and sequencing of MUTYH, and participated in the design of the study. SCB and MM performed the molecular genetic analysis in the Catalonian samples, participated in the design of the study, and helped to draft and revise the manuscript. CF carried out sequencing and analysis of APC in Galician samples and participated in the correction of the manuscript. JM and IM carried out the molecular genetic analysis in the Catalonian samples, mainly the analysis of large rearrangements in APC, FISH analysis of the APC gene and sequencing of MUTYH. ACas, FB and BG gathered clinical information. A Cas, AV and ACar helped to draft and revise the manuscript. CRP conceived the study, participated in its design and coordination, and wrote the manuscript. All authors read and approved the final manuscript.

\section{Additional material}

\section{Additional file 1}

Oligonucleotide sequences and PCR conditions used to amplify exons 1-14 of APC. Primer sequences and size of the amplification fragments were listed along with the PCR reaction and amplification conditions. Click here for file

[http://www.biomedcentral.com/content/supplementary/14712350-10-57-S1.doc]

\section{Additional file 2}

Oligonucleotide sequences and PCR conditions used to amplify exons 1-16 of MUTYH. Primer sequences and size of the amplification fragments were listed along with the PCR reaction and amplification conditions.

Click here for file

[http://www.biomedcentral.com/content/supplementary/14712350-10-57-S2.doc]

\section{Acknowledgements}

This work was supported by grants from the Fondo de Investigación Sanitaria (FIS 05/203I, 04/I I26, 05/007I, 08/0025, 08/I276), Xunta de Galicia (PGIDIT07PXIB9101209PR), Fundación de Investigación Médica Mutua Madrileña (to CRP, SCB and BG), Ministerio de Educación y Ciencia (SAF 07-64873), Asociación Española contra el Cáncer, Fundación Olga Torres (SCB), Acción Transversal contra el Cáncer (Instituto de Salud Carlos III) and Axudas para a intensificación da actividade investigadora dos profesionais dos centros do sistema sanitario público de Galicia RHI07/04 (Consellería de Sanidade, Xunta de Galicia) to CRP. CIBERER and CIBEREHD are funded by the Instituto de Salud Carlos III. NGF is supported by a Maria Barbeito's Fellowship from Xunta de Galicia, SCB is supported by a con- 
tract from the Fondo de Investigación Sanitaria (CP 03-0070, Ministerio de Sanidad), CF has obtained a FPU' Fellowship from the Ministerio de Educacion, FB received a research grant from Fundacion Caja Madrid, and IM is supported by a contract from the CIBERER.

We thank Maria Magdalena, Olga Lortes, Eva Fernández and Lourdes Costa-Boix for the excellent technical assistance in the analysis of samples.

We also thank the following hospitals for providing blood samples: Surgery and Oncology Departments from Hospital Clínico de Santiago, Oncology Department from Complexo Hospitalario de Pontevedra, Digestive Departments from Hospital Xeral Cíes de Vigo and Complexo Hospitalario de Ourense, Digestive and Oncology Departments from Hospital Xeral Calde de Lugo, Medicine Department from Hospital da Costa de Burela (Lugo).

\section{References}

I. Sieber OM, Tomlinson IP, Lamlum H: The adenomatous polyposis coli (APC) tumour suppressor-genetics, function and disease. Molecular Medicine Today 2000, 6(I 2):462-469.

2. Knudsen AL, Bisgaard ML, Bulow S: Attenuated familial adenomatous polyposis (AFAP). A review of the literature. Familial Cancer 2003, 2(I):43-55.

3. Lustig B, Behrens J: The Wnt signaling pathway and its role in tumor development. Journal of Cancer Research and Clinical Oncology 2003, I 29(4): 199-221.

4. Beroud C, Soussi T: APC gene: database of germline and somatic mutations in human tumors and cell lines. Nucleic Acids Research 1996, 24(I): I21-124.

5. Soravia C, Berk T, Madlensky L, Mitri A, Cheng H, Gallinger S, Cohen $\mathrm{Z}$, Bapat B: Genotype-phenotype correlations in attenuated adenomatous polyposis coli. American Journal of Human Genetics 1998, 62(6): |290-|30|

6. Armstrong JG, Davies DR, Guy SP, Frayling IM, Evans DG: APC mutations in familial adenomatous polyposis families in the Northwest of England. Human Mutation I997, I 0(5):376-380.

7. Al-Tassan N, Chmiel NH, Maynard J, Fleming N, Livingston AL, Williams GT, Hodges AK, Davies DR, David SS, Sampson JR, et al.: Inherited variants of MYH associated with somatic G:C-->T:A mutations in colorectal tumors. Nature Genetics 2002, 30(2):227-232.

8. Sieber OM, Lipton L, Crabtree M, Heinimann K, Fidalgo P, Phillips RK, Bisgaard ML, Orntoft TF, Aaltonen LA, Hodgson SV, et al.: Multiple colorectal adenomas, classic adenomatous polyposis, and germ-line mutations in MYH. The New England Journal of Medicine 2003, 348(9):791-799.

9. Marra G, Jiricny J: Multiple Colorectal Adenomas-is their number up? The New England Journal of Medicine 2003, 348(9):845-847.

10. Ruiz-Ponte C, Vega A, Carracedo A, Barros F: Mutation analysis of the adenomatous polyposis coli (APC) gene in northwest Spanish patients with familial adenomatous polyposis (FAP) and sporadic colorectal cancer. Human Mutation 200I, I 8(4):355.

II. Sieber OM, Lamlum H, Crabtree MD, Rowan AJ, Barclay E, Lipton L, Hodgson S, Thomas HJ, Neale K, Phillips RK, et al.: Whole-gene APC deletions cause classical familial adenomatous polyposis, but not attenuated polyposis or "multiple" colorectal adenomas. Proceedings of the National Academy of Sciences 2002, 99(5):2954-2958.

12. Aretz S, Stienen D, Uhlhaas S, Pagenstecher C, Mangold E, Caspari R, Propping $P$, Friedl W: Large submicroscopic genomic APC deletions are a common cause of typical familial adenomatous polyposis. British Medical Journal 2005, 42(2): I85-192.

13. Lamlum H, llyas M, Rowan A, Clark S, Johnson V, Bell J, Frayling I, Efstathiou J, Pack K, Payne S, et al.: The type of somatic mutation at APC in familial adenomatous polyposis is determined by the site of the germline mutation: a new facet to Knudson's 'twohit' hypothesis. Nature Medicine 1999, 5(9): I07| - 075.

14. Giarola M, Stagi L, Presciuttini S, Mondini P, Radice MT, Sala P, Pierotti MA, Bertario L, Radice P: Screening for mutations of the APC gene in 66 Italian familial adenomatous polyposis patients: evidence for phenotypic differences in cases with and without identified mutation. Human Mutation I999, I3(2): I I6-I 23.

15. Vandrovcova J, Stekrova J, Kebrdlova V, Kohoutova M: Molecular analysis of the APC and MYH genes in Czech families affected by FAP or multiple adenomas: I 3 novel mutations. Human Mutation 2004, 23(4):397.

16. Nagase H, Miyoshi Y, Horii A, Aoki T, Petersen GM, Vogelstein B, Maher E, Ogawa M, Maruyama M, Utsunomiya J: Screening for germ-line mutations in familial adenomatous polyposis patients: 61 new patients and a summary of 150 unrelated patients. Human Mutation 1992, I(6):467-473.

17. Dobbie Z, Spycher M, Mary J, Haner M, Guldenschuh I, Hurliman R, Amman R, Roth J, Muller H, Scott RJ: Correlation between the development of extracolonic manifestations in FAP patients and mutations beyond codon I403 in the APC gene. Journal of Medical Genetics 1996, 33(4):274-280.

18. Miyoshi Y, Ando H, Nagase H, Nishisho I, Horii A, Miki Y, Mori T, Utsunomiya J, Baba S, Petersen G: Germ-line mutations of the APC gene in $\mathbf{5 3}$ familial adenomatous polyposis patients. Proceedings of the National Academy of Sciences 1992, 89( I 0):4452-4456.

19. Li G, Tamura K, Yamamoto Y, Sashio H, Utsunomiya J, Yamamura T, Shimoyama T, Furuyama J: Molecular and clinical study of familial adenomatous polyposis for genetic testing and management. Journal of Experimental Clinical Cancer Research 1999, I 8(4):519-529.

20. Won YJ, Park KJ, Kwon HJ, Lee JH, Kim JH, Kim YJ, Chun SH, Han HJ, Park JG: Germline mutations of the APC gene in Korean familial adenomatous polyposis patients. Journal of Human Genetics 1999, 44(2): 103-108.

21. Nielsen M, Franken PF, Reinards TH, Weiss MM, Wagner A, Klift H van der, Kloosterman S, Houwing-Duistermaat J], Aalfs CM, Ausems $M G$, et al:: Multiplicity in polyp count and extracolonic manifestations in 40 Dutch patients with MYH associated polyposis coli (MAP). Journal of Medical Genetics 2005, 42(9):e54.

22. Isidro G, Laranjeira F, Pires A, Leite J, Regateiro F, Castro e Sousa F, Soares J, Castro C, Giria J, Brito MJ, et al.: Germline MUTYH (MYH) mutations in Portuguese individuals with multiple colorectal adenomas. Human Mutation 2004, 24(4):353-354.

23. Primer3 Software [http://frodo.wi.mit.edu/]

24. Orita M, Iwahana H, Kanazawa H, Hayashi K, Sekiya T: Detection of Polymorphisms of Human DNA by Gel Electrophoresis as Single-Strand Conformation Polymorphisms. Proceedings of the National Academy of Sciences 1989, 86(8):2766-2770.

25. Schouten JP, McElgunn CJ, Waaijer R, Zwijnenburg D, Diepvens F, Pals $G$ : Relative quantification of $\mathbf{4 0}$ nucleic acid sequences by multiplex ligation-dependent probe amplification. Nucleic Acids Research 2002, 30(1 2):e57.

26. Balaguer F, Castellvi-Bel S, Castells A, Andreu M, Munoz J, Gisbert JP, Llor X, Jover R, de Cid R, Gonzalo V: Identification of MYH Mutation Carriers in Colorectal Cancer: A Multicenter, CaseControl, Population-Based Study. Clinical Gastroenterology and Hepatology 2007, 5(3):379-387.

27. Polyphen: Prediction of funtional effect of humannsSNPs [http://genetics.bwh.harvard.edu/pph/]

28. Michils G, Tejpar S, Thoelen R, van Cutsem E, Vermeesch JR, Fryns JP, Legius E, Matthijs G: Large deletions of the APC gene in I5\% of mutation-negative patients with classical polyposis (FAP): a Belgian study. Human Mutation 2005, 25(2): I25-I34.

29. Nieuwenhuis $\mathrm{MH}$, Vasen HFA: Correlations between mutation site in APC and phenotype of familial adenomatous polyposis (FAP): A review of the literature. Critical Reviews in Oncology and Hematology 2007, 6 I (2): I53-16I.

30. Tomlinson IP, Neale K, Talbot IC, Spigelman AD, Williams CB, Phillips RK, Bodmer WF: A modifying locus for familial adenomatous polyposis may be present on chromosome I p35-p36. Journal of Medical Genetics 1996, 33(4):268-273.

31. Goss KH, Groden J: Biology of the adenomatous polyposis coli tumor suppressor. Journal of Clinical Oncology 2000, I 8(9): 1967-1979.

32. Fearnhead NS, Britton MP, Bodmer WF: The ABC of APC. Human Molecular Genetics 200I, I0(7):721-733.

33. Aretz S, Uhlhaas S, Caspari R, Mangold E, Pagenstecher C, Propping $P$, Friedl W: Frequency and parental origin of de novo APC mutations in familial adenomatous polyposis. European Journal of Human Genetics 2004, I 2(I):52-58. 
34. Stekrova J, Sulova M, Kebrdlova V, Zidkova K, Kotlas J, llencikova D, Vesela K, Kohoutova M: Novel APC mutations in Czech and Slovak FAP families: clinical and genetic aspects. BMC Medical Genetics 2007, 8: 16.

35. Gonzalez S, Blanco I, Campos O, Julia M, Reyes J, Llompart A, Cabeza E, Germa JR, Obrador A, Capella G: Founder mutation in familial adenomatous polyposis (FAP) in the Balearic Islands. Cancer Genetics and Cytogenetics 2005, I 58(I):70-74.

36. Salas A, Comas D, Lareu MV, Bertranpetit J, Carracedo A: mtDNA analysis of the Galician population: a genetic edge of European variation. European Journal of Human Genetics 1998, 6(4):365-375

37. Salas A, Lareu V, Calafell F, Bertranpetit J, Carracedo A: mtDNA hypervariable region II (HVII) sequences in human evolution studies. European Journal of Human Genetics 2000, 8( I 2):964-974.

38. Vega A, Torres M, Martinez Jl, Ruiz-Ponte C, Barros F, Carracedo A: Analysis of BRCAI and BRCA2 in breast and breast/ovarian cancer families shows population substructure in the Iberian peninsula. Annals of Human Genetics 2002, 66(I):29-36.

39. Nielsen M, Hes FJ, Nagengast FM, Weiss MM, Mathus-Vliegen EM, Morreau H, Breuning MH, Wijnen JT, Tops CM, Vasen HFA: Germline mutations in APC and MUTYH are responsible for the majority of families with attenuated familial adenomatous polyposis. Clinical Genetics 2007, 7 I(5):427-433.

40. Kairupan CF, Meldrum CJ, Crooks R, Milward EA, Spigelman AD, Burgess B, Groombridge C, Kirk J, Tucker K, Ward R, et al.: Mutation analysis of the MYH gene in an Australian series of colorectal polyposis patients with or without germline APC mutations. International Journal of Cancer 2005, I I 6( I):73-77.

4I. Lipton L, Tomlinson IP: The multiple colorectal adenoma phenotype and $\mathrm{MYH}$, a base excision repair gene. Clinical Gastroenterology and Hepatology 2004, 2(8):633-638.

42. Le Page F, Randrianarison V, Marot D, Cabannes J, Perricaudet M, Feunteun J, Sarasin A: BRCAI and BRCA2 Are Necessary for the Transcription-Coupled Repair of the Oxidative 8-Oxoguanine Lesion in Human Cells I. Cancer Research 2000, 60(19):5548-5552.

43. Vasen HFA, Moslein G, Alonso A, Aretz S, Bernstein I, Bertario L, Blanco I, Bulow S, Burn J, Capella G, et al.: Guidelines for the clinical management of familial adenomatous polyposis (FAP). Gut 2008, 57(5):704-7I3.

44. Riegert-Johnson DL, Johnson RA, Rabe KG, Wang L, Thomas B, Baudhuin LM, Thibodeau SN, Boardman LA: The Value of MUTYH Testing in Patients with Early Onset Microsatellite Stable Colorectal Cancer Referred for Hereditary Nonpolyposis Colon Cancer Syndrome Testing. Genetic Testing 2007, I I(4):361-366.

45. Bai H, Jones S, Guan X, Wilson TM, Sampson JR, Cheadle JP, Lu AL: Functional characterization of two human MutY homolog (hMYH) missense mutations (R227W and V232F) that lie within the putative hMSH6 binding domain and are associated with hMYH polyposis. Nucleic Acids Research 2005, 33(2):597-604.

46. Aceto G, Cristina Curia M, Veschi S, De Lellis L, Mammarella S, Catalano T, Stuppia L, Palka G, Valanzano R, Tonelli F, et al.: Mutations of APC and MYH in unrelated Italian patients with adenomatous polyposis coli. Human Mutation 2005, 26(4):394.

\section{Pre-publication history}

The pre-publication history for this paper can be accessed here:

\section{http://www.biomedcentral.com/1471-2350/10/57/pre} pub
Publish with BioMed Central and every scientist can read your work free of charge

"BioMed Central will be the most significant development for disseminating the results of biomedical research in our lifetime. "

Sir Paul Nurse, Cancer Research UK

Your research papers will be:

- available free of charge to the entire biomedical community

- peer reviewed and published immediately upon acceptance

- cited in PubMed and archived on PubMed Central

- yours - you keep the copyright
BioMedcentral 